\title{
Identification of a Pollution Source Power in the Kazantip Bay Applying the Variation Algorithm
}

\author{
V.S. Kochergin, S.V. Kochergin \\ Marine Hydrophysical Institute, Russian Academy of Sciences, Sevastopol, \\ Russian Federation \\ e-mail: vskocher@gmail.com
}

\begin{abstract}
The transport model of passive admixture in the Azov Sea is considered. On its basis the variational algorithm of identification power source pollution, including a variable in space, is implemented. The algorithm operability of optimum space distribution search of power source with measurements data is shown on a test example. Test calculations for the Kazantip Bay under east wind stress were carried out. The measurement data assimilation algorithm in the passive admixture transfer model is implemented applying gradient methods for optimal estimate retrieval. The retrieval is carried out by means of minimizing a quadratic function of prediction quality. The linked problem solving is used in the gradient of quality functional construction. On the basis of the variational method of data assimilation, the optimal estimate retrieval algorithm for pollution source power identification is constructed. In application of the algorithm, the integration of the main, linked and variational problems is implemented. The latter is solved to determine an iteration parameter when performing gradient descent. Integration problems are solved using TVD approximations. For the application of the procedure, the Sea of Azov flow fields and turbulent diffusion coefficients are obtained using the sigma coordinate ocean model (POM) under the eastern wind stress conditions being dominant at the observed period of time. Furthermore, the results can be used to perform numerical data assimilation on loads of suspended matter.
\end{abstract}

Keywords: power source identification, variation algorithm, discrepancy functional, concentration field, measurement data assimilation, the Azov Sea.

DOI: 10.22449/1573-160X-2015-2-69-76

(C) 2015, V.S. Kochergin, S.V. Kochergin

(c) 2015, Physical Oceanography

Introduction. Studying the admixture distribution dynamics the application of the both contemporary mathematical models [1] and the methods of measurement data assimilation [2, 3], allowing identifying the model input parameters, is necessary. Measurement data assimilation algorithms are mainly based on the forecast quality quadratic functional minimization featuring the decline of model solution from measurement data. At the same time the passive admixture transport model acts as a limitation of the input parameter variation. In the work [4] the variation algorithm of power source identification for two-dimensional model is thoroughly considered, its efficiency in the presence of measurement data on the pollution spot periphery in case of point source effect by time constant and variable power is also shown. In the present work such approach is applied to threedimensional model of passive admixture transport model in the Azov Sea. The task to identify the constantly acting pollution source power space variable is considered.

Variation algorithm of measurement data assimilation. Below we consider the passive admixture transport model in $\sigma$-coordinates

$$
\frac{\partial D}{\partial t}+\frac{\partial D}{\partial x}+\frac{\partial D}{\partial y}+\frac{U W}{\partial \sigma}=\frac{V \partial}{\partial x} A_{H} \frac{C \partial D C C}{\partial x}+\frac{\partial}{\partial y} A_{H} \frac{\partial \mathbb{C}}{\partial y}+\frac{\partial}{\partial \sigma} \frac{K}{D} \frac{\partial \mathbb{C}}{\partial \sigma}
$$

PHYSICAL OCEANOGRAPHY NO. 2 (2015) 
with the side boundaries

$$
\Gamma: \frac{\partial C}{\partial n}=0
$$

and mixed boundaries on the surface and at the bottom

$$
\sigma=0: \frac{\partial C}{\partial \sigma}=\bar{Q}_{S} \delta\left(x-x_{0}, y-y_{0}\right), \quad \sigma=-1: \frac{\partial C}{\partial \sigma}=\bar{Q}_{B} \delta\left(x-x_{0}, y-y_{0}\right),
$$

or

$$
\sigma=0: \frac{\partial C}{\partial \sigma}=Q_{S}(x, y), \quad \sigma=-1: \frac{\partial C}{\partial \sigma}=Q_{B}(x, y)
$$

and initial data

$$
C(x, y, \sigma, 0)=C_{0}(x, y, \sigma),
$$

where $t$ is the time; $x_{0}, y_{0}$ are the point source coordinates; $D$ is the dynamic depth; $C$ is the admixture concentration; $C_{0}$ is the initial admixture concentration; $U, V, W$ are the velocity field components; $A_{H}$ and $K$ are horizontal and vertical diffusion components correspondingly; $n$ is normal to the side boundary.

Under the conditions (3) $\bar{Q}_{S}, \bar{Q}_{B}=$ const, and in the (4) $Q_{S}(x, y), Q_{B}(x, y)$ are variable powers of the source in the surface and at the bottom accordingly.

Measurement data assimilation task $C_{\text {mes }}$ consists in minimizing the quadratic functional

$$
I_{0}=\frac{1}{2}\left(P\left(C-C_{\text {mes }}\right), P\left(C-C_{\text {mes }}\right)\right)_{M_{t}},
$$

where $M_{t}=M \times[0, T] ; M$ is integration domain; $P$ is zero extension operator of the discrepancy functions, defined on the set of measuring points; scalar product is determined by a standard method. Minimization (6) with the boundary conditions (4) is equivalent to finding the extremum of the following functional:

$$
\begin{aligned}
& I=I_{0}+\left(\frac{\partial D C}{\partial t}+\frac{\partial D U C}{\partial x}+\frac{\partial D V C}{\partial y}+\frac{\partial W C}{\partial \sigma}-\frac{\partial}{\partial x} A_{H} \frac{\partial D C}{\partial x}-\right. \\
& \left.-\frac{\partial}{\partial y} A_{H} \frac{\partial D C}{\partial y}-\frac{\partial}{\partial \sigma} \frac{K}{D} \frac{\partial C}{\partial \sigma}, C^{*}\right)_{M_{t}}+\left(\frac{\partial C}{\partial n}, C^{*}\right)_{\Gamma_{t}}+\left(\left.C\right|_{t=0}-C_{0},\left.C^{*}\right|_{t=0}\right)_{M}+ \\
& +\left(\frac{\partial C}{\partial \sigma}-Q_{S}(x, y), C^{*}\right)_{\sigma_{t}^{0}}+\left(\frac{\partial C}{\partial \sigma}-Q_{B}(x, y), C^{*}\right)_{\sigma_{t}^{-1}} .
\end{aligned}
$$

Writing variation of the functional (7) and integrating by parts, taking into account the boundary conditions and the continuity equation analogue to the $\sigma$ coordinates

we obtain

$$
\frac{\partial D}{\partial t}+\frac{\partial D U}{\partial x}+\frac{\partial D V}{\partial y}+\frac{\partial W}{\partial \sigma}=0
$$

$$
\delta I=\left(\delta Q_{S}(x, y), C^{*}\right)_{\sigma_{t}^{0}}+\left(\delta Q_{B}(x, y), C^{*}\right)_{\sigma_{t}^{-1}},
$$


where $C^{*}$ are Lagrange multipliers selected from the following solutions of the adjoint problem:

$$
\begin{gathered}
-\frac{\partial D C^{*}}{\partial t}-\frac{\partial D U C^{*}}{\partial x}-\frac{\partial D V C^{*}}{\partial y}-\frac{\partial W C^{*}}{\partial \sigma}-D \frac{\partial}{\partial x} A_{H} \frac{\partial C^{*}}{\partial x}- \\
-D \frac{\partial}{\partial y} A_{H} \frac{\partial C^{*}}{\partial y}-\frac{\partial}{\partial \sigma} \frac{K}{D} \frac{\partial C^{*}}{\partial \sigma}=-P\left(C-C_{\text {mes }}\right), \\
\Gamma: \frac{\partial C^{*}}{\partial n}=0, \sigma=0: \frac{\partial C^{*}}{\partial \sigma}=0, \sigma=-1: \frac{\partial C^{*}}{\partial \sigma}=0, \\
t=T: C^{*}=0 .
\end{gathered}
$$

In the case where the measurement data are available on the final instant of time $T$, in (10) we define the right side equal to zero, while in $t=T$ (12) we use the following condition

$$
t=T: C^{*}=P\left(C_{\text {mes }}-C\right) .
$$

From the stationary condition of the functional (7) and the definition of the functional gradient we have

$$
\begin{gathered}
\nabla_{Q_{S}} I=\int_{0}^{T} C^{*}(x, y, 0, t) d t, \\
\nabla_{Q_{B}} I=\int_{0}^{T} C^{*}(x, y,-1, t) d t .
\end{gathered}
$$

Similarly, for the boundary conditions (3) we can obtain

$$
\begin{gathered}
\nabla_{\bar{Q}_{S}} I=\int_{0}^{T} C^{*}\left(x_{0}, y_{0}, 0, t\right) d t, \\
\nabla_{\bar{Q}_{B}} I=\int_{0}^{T} C^{*}\left(x_{0}, y_{0},-1, t\right) d t .
\end{gathered}
$$

Further iterative descent is carried out in the direction of the corresponding functional gradient.

The results of numerical experiments. Numerical experiments were carried out applying the model of the work [1] to the Azov Sea. To test the algorithm, the identification of variations in the power source the calculation to establish the model the flow field under the influence of constant wind eastern direction at a speed of $10 \mathrm{~m} / \mathrm{s}$ was performed in Kazantip Bay. As a result of simulation the spatial distribution coefficients were also obtained. The velocity fields and turbulent diffusion coefficients were used as input data in the integration model of passive admixture transport for a period of 10 days. 


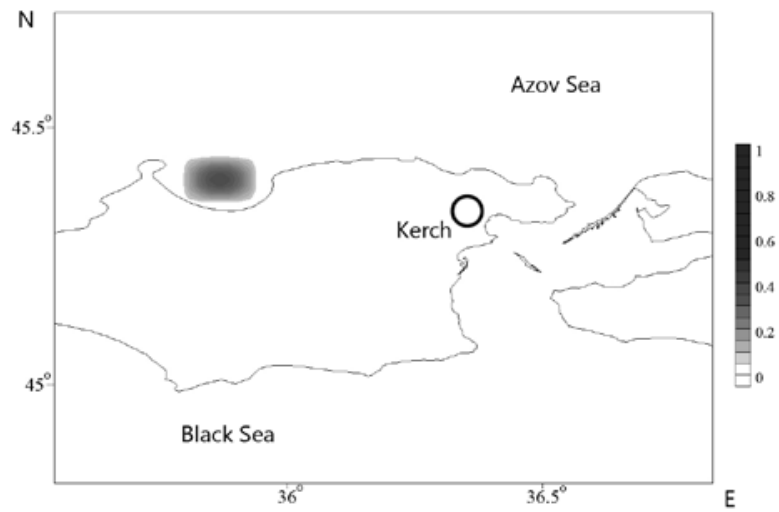

Fig. 1. Pollution area $\Omega$ and absolute power values of the source $Q_{B}$

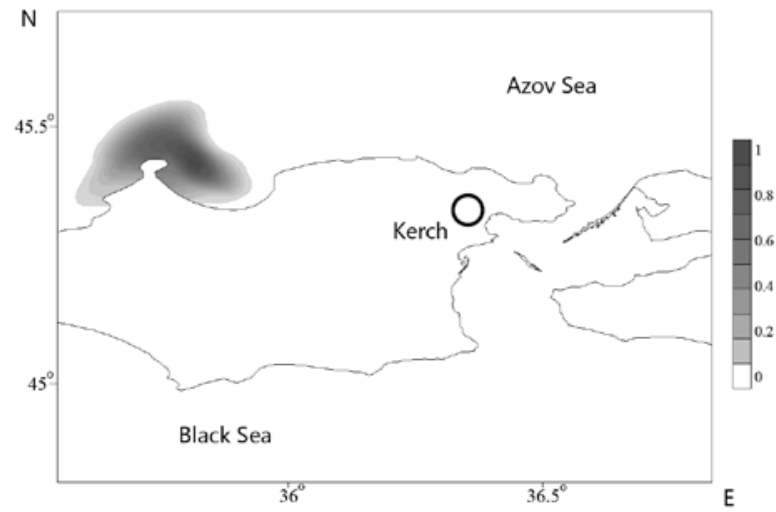

Fig. 2. Pollution concentration area under the eastern wind effect and power space variable of the source

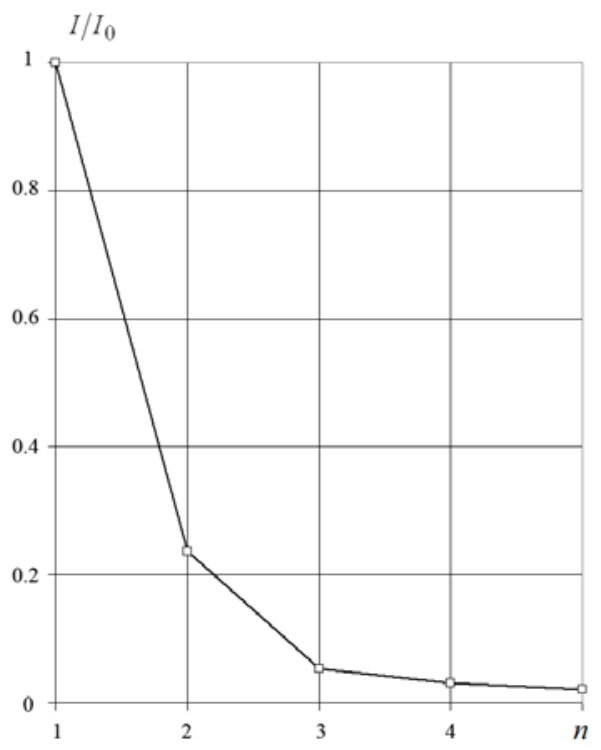

Fig. 3. The fall of the normalized values of the forecast quality functional depending on the iteration number $n$ under power space variable of the source $Q_{B}$ 
Fig. 4, 5 show absolute power values of the source $Q_{B}$ on the first and twentieth iterations of the algorithm identification. It is evident that in the process of iterations correspondence of the found power $Q_{B}$ (Fig. 5) to the initial one (Fig.1) significantly improves. Decreasing the total data amount of spatial structure of the concentration field the convergence of the iterative process slows down. Identification process considerably accelerates, if $Q_{B}$ in this area is a constant value, then to achieve the minimum of functional applying this procedure, only one iteration is necessary. It should be noted that $Q_{B}=$ const in the area $\Omega$ can be evaluated in another way, for instance, by method of linearization or by adjoint method.

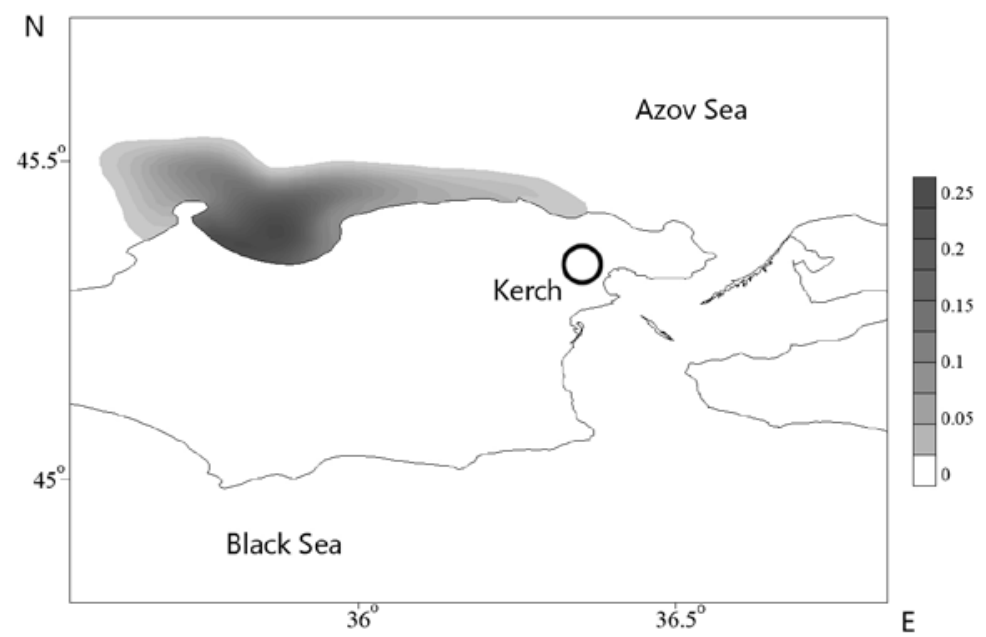

Fig. 4. Absolute power value of the source $Q_{B}$ on the first iteration of identification variation algorithm

The applied algorithm permits to restore the spatial flow structure of the matter. In the present work without loss of generality the value $Q_{B}$ is considered. The problem for $Q_{S}$ is solved similarly. In the article [4] the performance of the algorithm in identifying the variable power time $Q(t)$ is shown. The main requirement in this case is sufficient amount of information for the convergence of the iterative process. It is clear that $C_{\text {mes }}$ cannot belong to a single instant of time $T$, but relate to different instants of time $t \in[0, T]$. In accordance with the work [5], the model in the given algorithm acts as a spatio-temporal interpolator, therefore it is also important that the total amount of information is sufficient for the convergence of the iteration process. The most informative are measuring points in the area of the maximum values of the concentration field and in the areas with a substantial information relation to the area $\Omega$. These points can be determined by influence function based on the solving of the corresponding adjoint problems. 


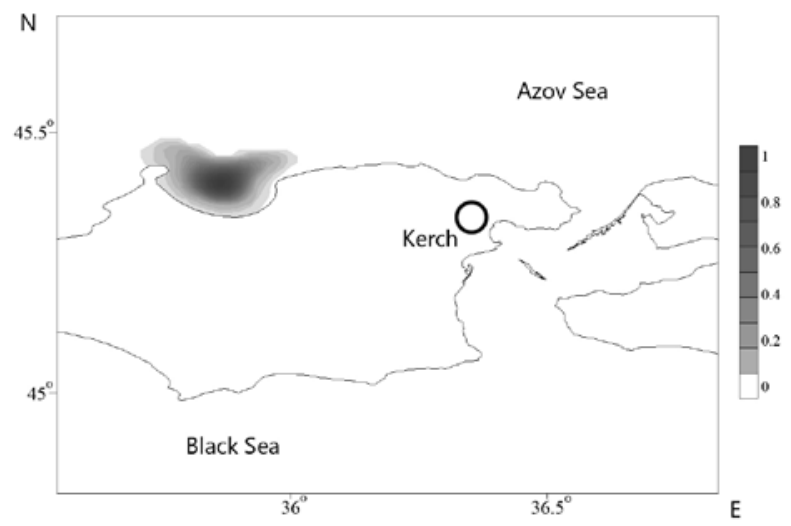

Fig. 5. Absolute power value of the source $Q_{B}$ on the twentieth iteration of identification variation algorithm

Simulation of the pollution distribution from a permanent unit power source was carried out at different wind effect. The software code provides a reference source both on the sea surface $\bar{Q}_{S}=1$ and at the bottom $\bar{Q}_{B}=-1$. Now we are to consider the case $\bar{Q}_{B}=-1$ in Kazantip Bay under the eastern wind. Under such wind effect an intense "airing" of the Bay takes place, and the admixture distributes to the north-west (Fig. 6). Under assimilation as the measurement data the information taken from the periphery of the contamination area (to the left of the vertical line) is used. Fig. 6, 7 show the scale of values of the concentration field, normalized to the respective maximum values.

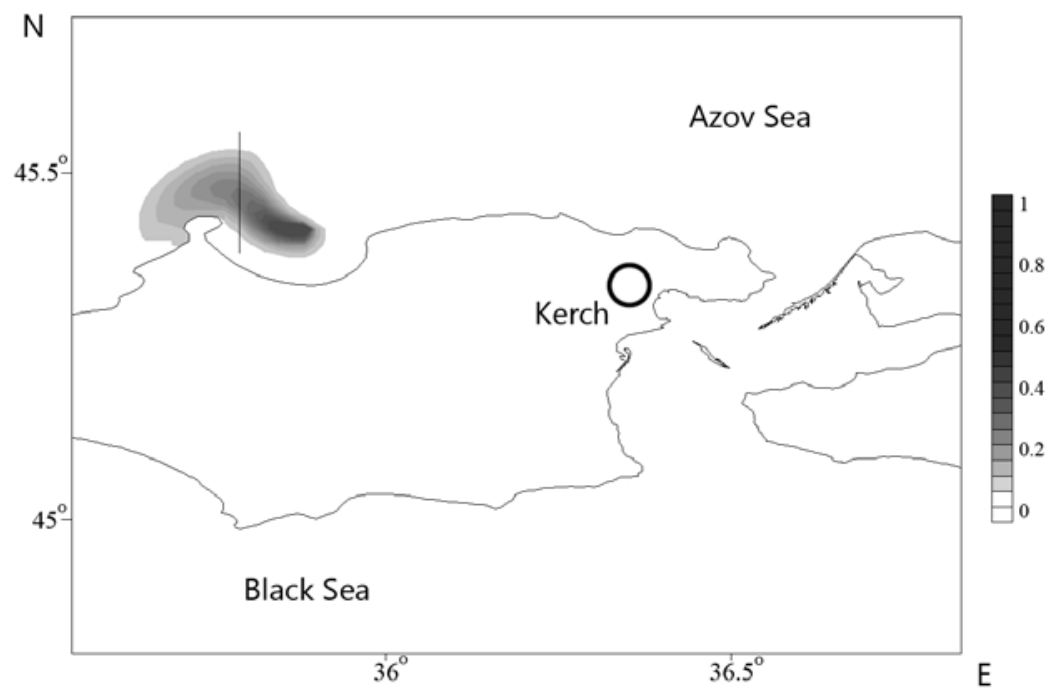

Fig. 6. Pollution concentration field under the eastern wind effect and permanent point source 


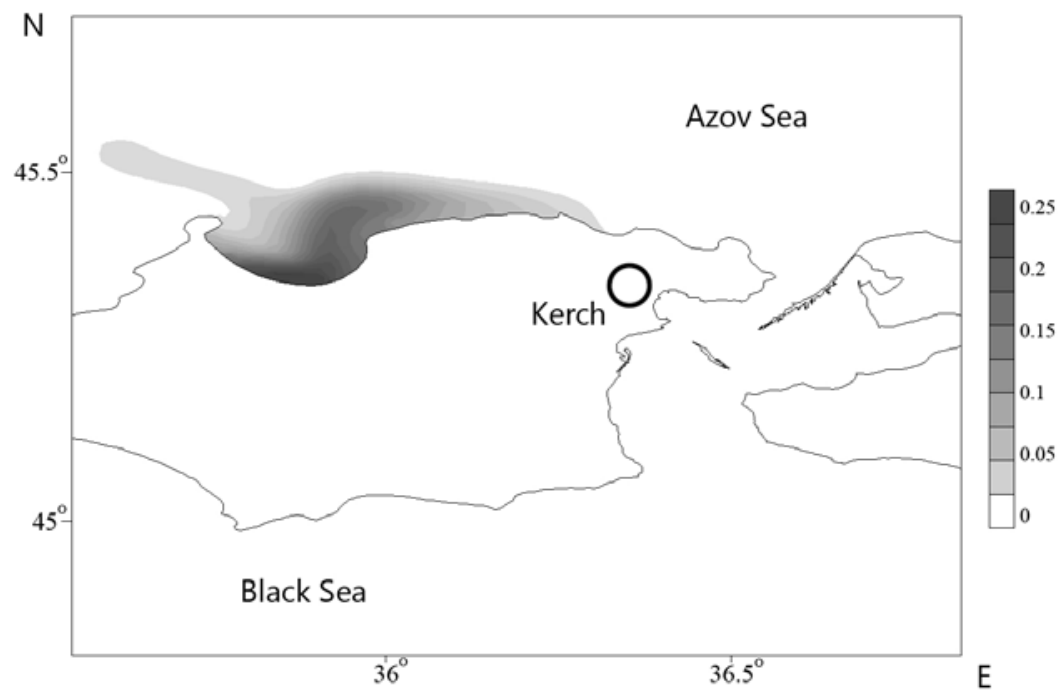

Fig. 7. Influence function (adjoint problem solution)

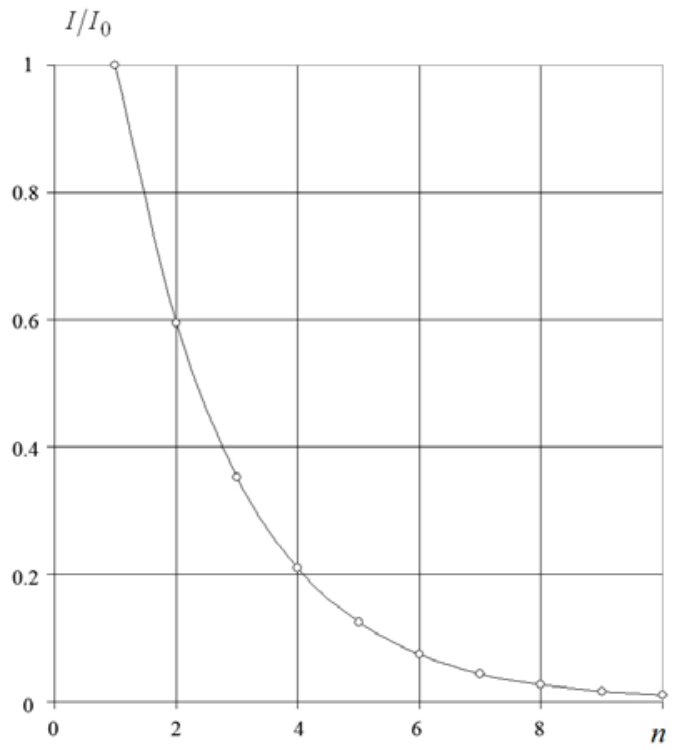

Puc. 8. The fall of the normalized value of the forecast quality functional depends on the number of iterations $n$ at a constant power source $Q_{B}$

As a result of the adjoint problem solution (10) - (12) under the first iteration we have the distribution $C^{*}$ at the instant of time $t=0$ (Fig. 7), featuring the forecast discrepancy influence on the power $\bar{Q}_{B}$ in the point $\left(x_{0}, y_{0}\right)$. In the process of iterations (Fig. 8) the fall of the normalized value of the forecast quality functional takes place and the known value $\bar{Q}_{B}$ restores. Results of the numeric experiments showed convergence of the iterative process to depend on the amount PHYSICAL OCEANOGRAPHY NO. 2 (2015) 
of information assimilated. In case of assimilation of all the simulated field information at a finite time to reach the minimum of a functional one iteration is required. The greatest information value the points situated closer to the source of pollution possess.

The article [4] demonstrates that for the time variable of the source power $Q(t)$ information about the entire concentration field at a finite time is necessary. Taking into consideration the possibility of time and space measurement data distribution, it can also be argued that for a more accurate identification of $Q(t)$, it is necessary to have the point of measurement in the area adjacent to the source of pollution.

Conclusion. In general, the performed numerical experiments showed the reliable operation of the variation algorithm of power source identification in relation to the model of passive admixture transport in the Azov Sea. The results can be used to solve various problems of ecological orientation in the study of the impact of anthropogenic pollution sources in the waters of the Azov and Black Sea.

\section{REFERENCES}

1. Ivanov, V.A., Fomin, V.V., 2008, "Matematicheskoe modelirovanie dinamicheskikh protsessov $v$ zone more - susha [Mathematic modeling of the dynamic processes in the zone sea-land]", Sevastopol, ECOSI-Gidrofizika, 363 p. (in Russian).

2. Kochergin, S.V., Kochergin, V.S. \& Fomin, V.V., 2012, "Opredelenie kontsentratsii passivnoy primesi $v$ Azovskom more na osnove resheniya serii sopryazhennykh zadach [Determination of the passive admixture concentration in the Azov Sea based on the solution of the adjoint problems]", Ekologicheskaya bezopasnost' pribrezhnoy i shel'fovoy zon $i$ kompleksnoe ispol'zovanie resursov shel'fa, iss. 26, vol. 2, pp. 112-118 (in Russian).

3. Marchuk, G.I., Penenko, V.V., 1978, “Application of optimization methods to the problem of mathematical simulation of atmospheric processes and environment”, Modeling and Optimization of Complex Systems, Ed. G.I. Marchuk, Proc. of the IFIP-TC7 Working conf., New York, Springer, pp. 240-252.

4. Kochergin, V.S., Kochergin, S.V., 2010, “Ispol'zovanie variatsionnykh printsipov i resheniya sopryazhennoy zadachi pri identifikatsii vkhodnykh parametrov modeli perenosa passivnoy primesi [Application of adjoint problem principles and solution during the identification of the passive admixture transport model input parameters]", Ekologicheskaya bezopasnost' pribrezhnoy i shel'fovoy zon i kompleksnoe ispol'zovanie resursov shel'fa, iss. 22, pp. 240-244 (in Russian).

5. Penenko, V.V., 1981, "Metody chislennogo modelirovaniya atmosfernykh protsessov [Numerical simulation methods of the atmospheric processes]”, Leningrad, Gidrometeoizdat, 350 p. (in Russian). 